\title{
Synthesis of Biopolymer Blend- Metal Nitride Nanoparticles for Antibacterial Activity against E. coli
}

\author{
Ahmed Hashim* and Zinah Sattar Hamad \\ University of Babylon, College of Education for Pure Sciences, Department of Physics, Iraq
}

Correspondence Author: Ahmed Hashim. University of Babylon, College of Education for Pure Sciences, Department of Physics, Iraq

Received date: 22 July 2018, Accepted date: 22 October 2018, Online date: 1 November 2018

Copyright: (C) 2018 Hicham Boughendjioua. This is an open-access article distributed under the terms of the Creative Commons Attribution License, which permits unrestricted use, distribution, and reproduction in any medium, provided the original author and source are credited.

\begin{abstract}
Nanocomposites films of (polyvinyl alcohol - poly-acrylic acid) blend/ titanium nitride nanoparticles have been prepared by concentrations: polyvinyl alcohol (85 wt.\%), poly-acrylic acid (15 wt.\%) and titanium nitride nanoparticles were added to (PVA-PAA) blend with concentrations are $(1.5,3,4.5$, and 6$)$ wt. $\%$. The (PVA-PAA-TiN) nanocomposites were prepared by casting method for antibacterial application. The (PVA-PAA-TiN) nanocomposites were test for antibacterial against Escherichia coli (E. coli). The results showed that the (PVA-PAA-TiN) nanocomposites have antibacterial activity against Escherichia coli. The inhibition zone diameter increases with increase in TiN nanoparticles concentration.
\end{abstract}

Key words: Nanocomposites, E. coli, Antibacterial, Inhibition zone, Titanium nitride

\section{INTRODUCTION}

Nanotechnology is considered as new generation technology. This new field is greatly influencing the economy of the world by producing novel and great valued products, product usage and more efficient manufacturing methods. Nanotechnology is leading to the production of many types of nanoparticles such as metal, metal oxide, doped and un-doped metal and metal oxide etc. Moreover, nanoparticles show good antibacterial properties [1]. There has recently been a growing interest in developing antibacterial medical polymer materials. The reason for this attempt is the effort to reduce health complications caused by bacteria commonly found on various types of medical equipment. As the most types of the commonly applied polymers have no antibacterial action, they have to be modified to obtain polymer materials with the desired properties. The modification of virgin polymer with a bioactive agent is a possible method. In this case, the polymer is a carrier, providing transport and controlled release of bioactive substances into the environment where they are needed [2]. Poly (vinyl alcohol) is a bioadaptable, nonvenomous, water-soluble, and biodegradable synthetic polymer. Furthermore, PVA usually is used in biomedical fields [3]. Poly (vinyl alcohol), PVA, is a non-toxic, and has good physical and chemical properties and film-forming ability. The use of this polymer is important in many applications such as con- trolled drug delivery systems, membrane preparation, recycling of polymers and packaging. PVA has bioinertness and it has many uses in medical applications such as artificial pancreas, hemodialysis, nanofilteration, synthetic vitreous and implantable medical device [4].

Titanium nitride $(\mathrm{TiN})$ is a ceramic with great hardness $\left(2,000 \mathrm{~kg} / \mathrm{mm}^{2}\right)$, high decomposition temperature $\left(2,949^{\circ} \mathrm{C}\right)$, defect structure, i.e., deviation from stoichiometry, chemical stability at room temperature, superconductivity, and gold-yellow color. TiN is mainly used as a coating to enhance other materials. TiN shows encouraging blood tolerability properties with hemolysis percentage near zero. Therefore, TiN-coatings are used in cardiology for ventricular assist devices in patients with heart failure and for pacemaker leads. In neurology, TiN-coated electrodes are used in chronically implanted devices for the treatment of spinal cord injury. TiN-coating is also used in orthopedic implants, because of its excellent biological properties, such as the reduction of the release of cobalt-chromium-molybdenum ions, and the aesthetic appeal of the "golden color" [5]. Titanium nitride nanoparticles exhibit novel electronic, optical and mechanical properties such as high melting points and low sintering tendencies are beneficial for applications in high temperature catalysis [6]. Nanocomposites have unique properties that make them suitable for many different medical, industrial and environmental applications in fields: thermal energy storage and release [7-9], antibacterial [10-15], humidity sensors [16-20], pressure sensors and piezoelectric [21-26] and radiation shielding [27-30]. This work deals with synthesis of biofilms from biopolymer blend- metal nitride nanoparticles for antibacterial activity against E. coli. 


\section{MATERIALS AND METHODS}

Biopolymers blend films of polyvinyl alcohol- poly-acrylic acid and films of polyvinyl alcohol- poly-acrylic acid doped with titanium nitride nanoparticles were prepared by casting method by dissolving $1 \mathrm{gm}$ of polyvinyl alcohol and poly-acrylic acid in $30 \mathrm{ml}$ of distilled water by using magnetic stirrer to mix the polymers for 1 hour to obtain more homogeneous solution. The polymer blend was prepared with concentration ( $85 \mathrm{wt} . \%$ PVA, $15 \mathrm{wt} . \%$ PAA). The titanium nitride (TiN) nanoparticles were added to (PVA-PAA) blend with concentrations are (1.5, 3, 4.5 and 6) wt.\%. The samples were examined for antibacterial application by a disc diffusion method. The antibacterial test was done by using gram negative organisms (Escherichia coli). The disks of (PVA-PAA-TiN) nanocomposites samples were placed over the media and incubated at $37^{\circ} \mathrm{C}$ for 24 hours. The antibacterial test investigated by measuring the inhibition zone of nanocomposites samples.

\section{RESULTS AND DISCUSSION}

Figure 1 shows the optical microscope images at magnification power (40x) for different concentrations of TiN nanoparticles.
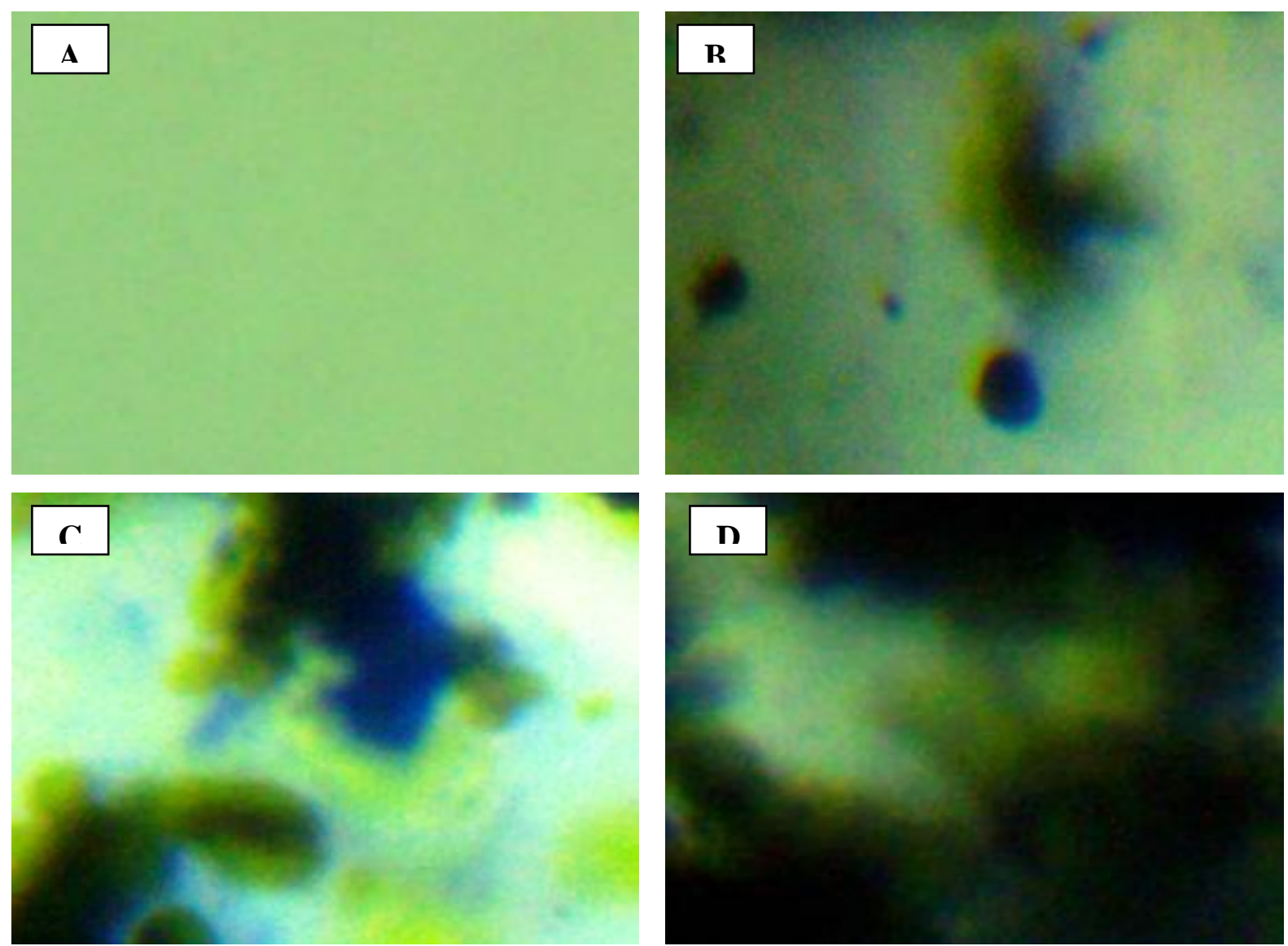

F.

Fig. 1. Photomicrographs (40X) for (PVA-PAA-TiN) nanocomposites:(A) for (PVA-PAA) blend, (B) for 1.5 wt.\% TiN, (C) for 3 wt.\% TiN,(D) for $4.5 \mathrm{wt} . \% \mathrm{TiN},(\mathrm{E})$ for $6 \mathrm{wt} . \% \mathrm{TiN}$. 
The figure shows that the TiN nanoparticles is aggregated as a cluster at lower concentrations. At high concentrations of TiN nanoparticles, the TiN nanoparticles form a paths network inside the (PVA-PAA) blend [31]. These results consistent with the results of researchers [32,33].The antibacterial properties of the (PVA-PAA-TiN) nanocomposites against gram- negative (Escherichia coli) are shown in figure 2. From the figure, the inhibition zone increases with increase the TiN nanoparticles concentrations. Nanoparticles possess unique physical, chemical, electronic, electrical, mechanical, magnetic, thermal, dielectric, optical, and biological properties. The electrostatic interaction of nanoparticles with negatively charged bacterial surfaces draws the particles to the bacteria and promotes their penetration into the membrane. A strongly positive zeta potential of a nanoparticle promotes nanoparticle interactions with cell membranes leading to membrane disruption, bacterial flocculation, and a reduction in viability. The generation of reactive oxygen species is also a mechanism of nanoparticle antibacterial activity. Further mechanisms of action of nanoparticles as antimicrobial agents include disrupting deoxyribonucleic acid during the replication and cell division of microorganisms, compromising the bacterial membrane integrity via physical interactions with the microbial cell (the physical presence of a nanoparticle most likely disrupts cell membranes in a dose-dependent manner), and releasing toxic metal ions and possessing abrasive properties which bring about lysis of cells [35].

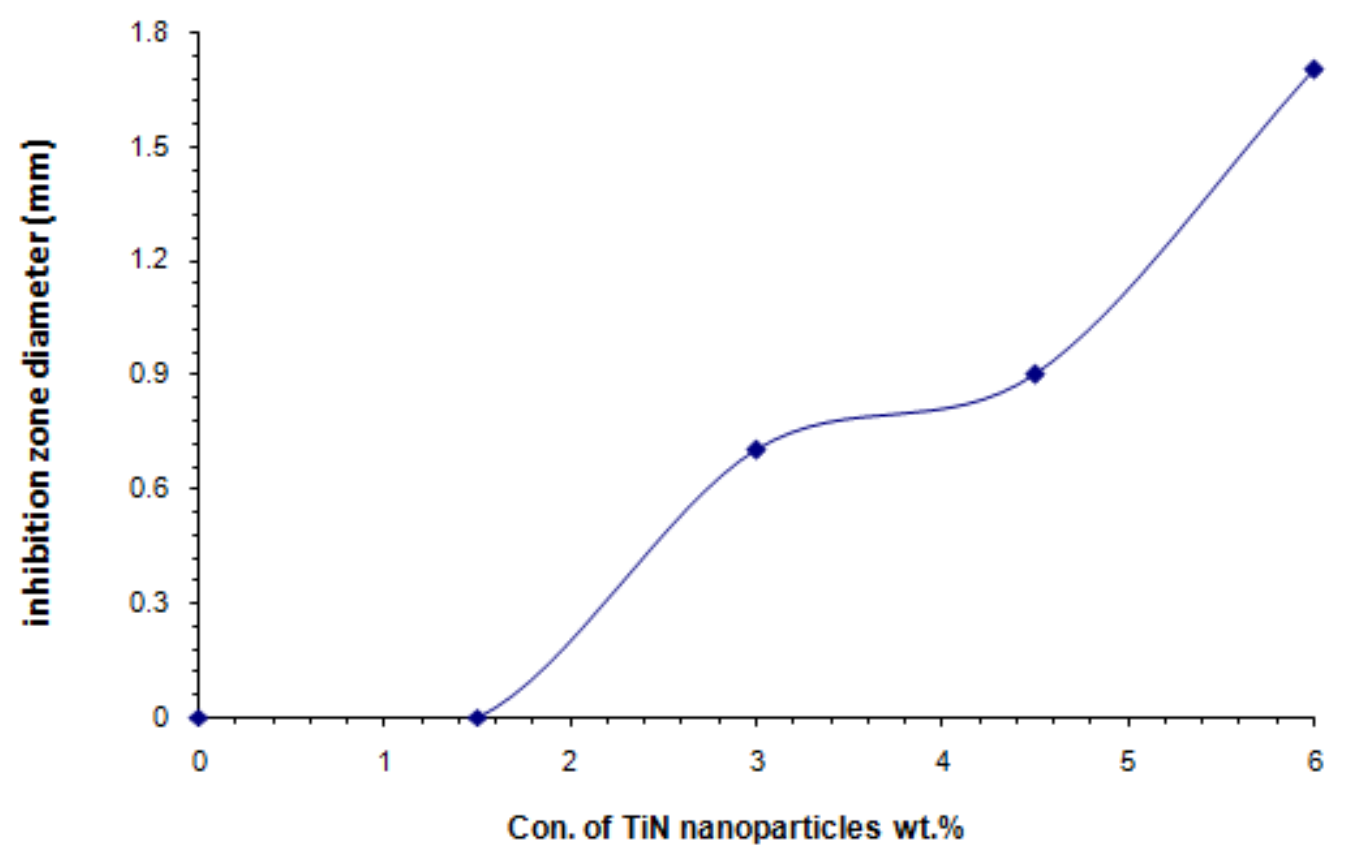

Fig. 2. Variation of inhibition zone diameter with TiN nanoparticles concentrations against Escherichia coli.

\section{CONCLUSIONS}

1- The optical microscope images of nanocomposites showed that the TiN nanoparticles at low concentrations is aggregated as a cluster. of TiN nanoparticles. The TiN nanoparticles form a paths network inside the (PVA-PAA) blend at high concentrations.

2- The inhibition zone diameter increases with increase in TiN nanoparticles concentrations against Escherichia coli.

3- The (PVA-PAA-TiN) nanocomposites have good antibacterial activity against Escherichia coli.

\section{REFERENCES}

[1] M. A. Qamar, S. Shahid, S. A. Khan, S. Zaman, M. N. Sarwar, Synthesis Characterization, Optical And Antibacterial Studies of Co-Doped SnO2 Nanoparticles, Digest Journal of Nanomaterials and Biostructures, Vol.12, No.4, (2017).

[2] Tsermaa Galya, Vladimı'r Sedlar`^'k, Ivo Kur`itka, Radko Novotny, Jana Sedlar`^1'kova' , Petr Sa'ha, Antibacterial Poly(vinyl Alcohol) Film Containing Silver Nanoparticles: Preparation and Characterization, Journal ofAppliedPolymer Science,Vol. 110, 3178-3185 (2008).

[3] Halime Serincay, Semiha O zkan, Nurdane Yılmaz, Serhat Koc,yigit, Ibrahim Uslu, Safa Gürcan, and Mustafa Arısoy, PVA/PAA-Based Antibacterial Wound Dressing Material with Aloe Vera, Polymer-Plastics Technology and Engineering, Vol.52, (2013).

[4] Umesh Kumar Parida1, Ashok Kumar Nayak, Birendra Kumar Binhani, P. L. Nayak, Synthesis and Characterization of Chitosan-Polyvinyl Alcohol Blended with Cloisite 30B for Controlled Release of the Anticancer Drug Curcumin, Journal of Biomaterials and Nanobiotechnology, Vol. 2, (2011).

[5] Koutaro Yamazaki, Izumi Mashima, Futoshi Nakazawa, Yasuhiro Nakanishi and Morio Ochi, Application of Dental Implants Coated with Titanium Nitride: The Experimental Study with Porphyromonas gingivalis Infection, Int. J. Curr. Microbiol. App. Sci., Vol. 6, No.1, (2017). 
Citation: Ahmed Hashim and Zinah Sattar Hamad, 2018. Synthesis of Biopolymer Blend- Metal Nitride Nanoparticles for Antibacterial Activity against E. coli. Global Journal of Medicinal Plant Research., 6(2): 1-5. DOI: 10.22587/gjmpr.2018.6.2.1

[6] Ahmed Al-Ghaban, Kadhum Mutter Shabeeb, and Aseel Hadi Hamaza, Influence of Titanium Nitride Nanoparticles on Microstructural, Physical and Mechanical Properties of Titanium Carbide, Materials Focus, Vol. 7, No.1, (2018).

[7] Ibrahim R. Agool, Kadhim J. Kadhim, Ahmed Hashim, Preparation of (polyvinyl alcohol-polyethylene glycol- polyvinyl pyrrolidinone-titanium oxide nanoparticles) nanocomposites: electrical properties for energy storage and release, International Journal of Plastics Technology, Vol.20, No. 1, PP. 121-127, (2016).

[8] Ibrahim R. Agool, Kadhim J. Kadhim, Ahmed Hashim, Synthesis of (PVA-PEG-PVP-ZrO ${ }_{2}$ ) Nanocomposites For Energy Release and Gamma Shielding Applications, International Journal of Plastics Technology, Vol.21, Issue 2, (2017).

[9] A. Hashim, I. R. Agool and K. J. Kadhim, Novel of (Polymer Blend-Fe $\mathrm{O}_{4}$ ) Magnetic Nanocomposites: Preparation and Characterization For Thermal Energy Storage and Release, Gamma Ray Shielding, Antibacterial Activity and Humidity Sensors Applications, Journal of Materials Science: Materials in Electronics, Vol. 29, Issue 12, pp. 10369-10394, (2018).

[10] Kadhim J. Kadhim, Ibrahim R. Agool and Ahmed Hashim, Effect of Zirconium Oxide Nanoparticles on Dielectric Properties of (PVA-PEG-PVP) Blend for Medical Application, Journal of Advanced Physics, Vol.6, No.2, (2017).

[11] Kadhim J. Kadhim, Ibrahim R. Agool and Ahmed Hashim, Synthesis of (PVA-PEG-PVP-TiO2) Nanocomposites for Antibacterial Application, Materials Focus, Vol.5, No.5, (2016).

[12] Farhan Lafta Rashid, Aseel Hadi, Naheda Humood Al-Garah, Ahmed Hashim, Novel Phase Change Materials, MgO Nanoparticles, and Water Based Nanofluids for Thermal Energy Storage and Biomedical Applications, International Journal of Pharmaceutical and Phytopharmacological Research, Vol.8, Issue 1, ( 2018).

[13] Naheda Humood Al-Garah, Farhan Lafta Rashid, Aseel Hadi, and Ahmed Hashim, Synthesis and Characterization of Novel (Organic-Inorganic) Nanofluids for Antibacterial, Antifungal and Heat Transfer Applications, Journal of Bionanoscience, Vol. 12, (2018).

[14] Ibrahim R. Agool, Kadhim J. Kadhim and Ahmed Hashim, Synthesis of (PVA- PEG-PVP-MgO) Nanobiomaterials and their Application, Advances in Environmental Biology, Vol.9, No.27, (2015).

[15] Kadhim J. Kadhim, Ibrahim R.Agool and Ahmed Hashim, Enhancement in Optical Properties of (PVA-PEG-PVP) Blend By the Addition of Titanium Oxide Nanoparticles For Biological Application, Advances in Environmental Biology, Vol.10, No.1, (2016).

[16] A. Hashim and Q. Hadi, Synthesis of Novel (Polymer Blend-Ceramics) Nanocomposites: Structural, Optical and Electrical Properties for Humidity Sensors, Journal of Inorganic and Organometallic Polymers and Materials, Vol.28, Issue 4, pp 1394-1401, (2018).

[17] Ahmed Hashim and Aseel Hadi, Synthesis and Characterization of ( $\left.\mathrm{MgO}-\mathrm{Y}_{2} \mathrm{O}_{3}-\mathrm{CuO}\right)$ Nanocomposites for Novel Humidity Sensor Application, Sensor Letters, Vol.15, (2017).

[18] I. R. Agool, K. J. Kadhim, A. Hashim, Fabrication of new nanocomposites: (PVA-PEG-PVP) blend-zirconium oxide nanoparticles) for humidity sensors, International Journal of Plastics Technology, Vol.21, Issue 2, (2017).

[19] A. Hadi, A. hashim, development of a new humidity sensor based on (carboxymethyl cellulose-starch) blend with copper oxide nanoparticles, Ukrainian Journal of Physics, Vol. 62, No. 12, (2017).

[20] A. Hashim and Q. Hadi, Structural, electrical and optical properties of (biopolymer blend/ titanium carbide) nanocomposites for low cost humidity sensors, Journal of Materials Science: Materials in Electronics, Vol.29, pp.11598-11604, (2018).

[21] Dalal Hassan and Ahmed Hashim, Preparation and Studying the Structural and Optical Properties of (Poly-Methyl Methacrylate-Lead Oxide) Nanocomposites for Bioenvironmental Applications, Journal of Bionanoscience, Vol. 12, (2018).

[22] Ahmed Hashim and Qassim Hadi, Novel of (Niobium Carbide/Polymer Blend) Nanocomposites: Fabrication and Characterization for Pressure Sensor, Sensor Letters, Vol.15, (2017).

[23] Ahmed Hashim, Majeed Ali Habeeb, Aseel Hadi, Qayssar M. Jebur, and Waled Hadi, Fabrication of Novel (PVA-PEGCMC-Fe3O4) Magnetic Nanocomposites for Piezoelectric Applications, Sensor Letters, Vol.15, No.12, (2017).

[24] Ahmed Hashim, Majeed Ali Habeeb, Abdulameer Khalaf, Aseel Hadi, Synthesis of Novel (Polymer Blend-Titanium Carbide) Nanocomposites and Studying their Characterizations for Piezoelectric Applications, Journal of University of Babylon, Pure and Applied Sciences, Vol. 26, No. 6, (2018).

[25] Ahmed Hashim and Aseel Hadi, A Novel Piezoelectric Materials Prepared from (Carboxymethyl Cellulose-Starch) BlendMetal Oxide Nanocomposites, Sensor Letters, Vol.15, No.12, (2017).

[26] Ahmed Hashim and Aseel Hadi, Novel Pressure Sensors Made From Nanocomposites (Biodegradable Polymers-Metal Oxide Nanoparticles): Fabrication And Characterization, Ukrainian Journal of Physics, Vol. 63, No. 8, (2018).

[27] A. Hashim and A. Hadi, novel lead oxide polymer nanocomposites for nuclear radiation shielding applications, Ukrainian Journal of Physics, Vol.62, No.11, (2017).

[28] Ahmed Hashim and Ali Jassim, Novel of Biodegradable Polymers-Inorganic Nanoparticles: Structural, Optical and Electrical Properties as Humidity Sensors and Gamma Radiation Shielding for Biological Applications, Journal of Bionanoscience, Vol. 12, (2018).

[29] Ahmed Hashim and Ali Jassim, Novel of (PVA-ST- $\left.\mathrm{PbO}_{2}\right)$ Bio Nanocomposites: Preparation and Properties for Humidity Sensors and Radiation Shielding Applications, Sensor Letters, Vol.15, No.12, (2017).

[30] M. A. Habeeb, A. Hashim, and A. Hadi, Fabrication of New Nanocomposites: CMC-PAA-PbO ${ }_{2}$ Nanoparticles for Piezoelectric Sensors and Gamma Radiation Shielding Applications, Sensor Letters, Vol.15, No.9, PP. 785-790, (2017).

[113] O. Abdullah, D. R. Saber and L. O. Hamasalih, Complexion Formation in PVA/PEO/CuCl ${ }_{2}$ Solid Polymer Electrolyte, Universal Journal of Materials Science, Vol. 3, No. 1, (2015). 
[31] Clara Silvestre, Donatella Duraccio, Antonella Marra, Valentina Strongone and Sossio Cimmino, Development of Antibacterial Composite Films Based on Isotactic Polypropylene and Coated ZnO Particles for Active Food Packaging, Coatings, Vol.6, (2016).

[32] Zhuangzhuang Chu, Tianrui Zhao, Lin Li, Jian Fan and Yuyue Qin, Characterization of Antimicrobial Poly (Lactic Acid)/Nano-Composite Films with Silver and Zinc Oxide Nanoparticles, Materials, Vol.10, (2017).

[33] M. Miranzadeh, M.Z. Kassaee, L. Sadeghi, M. Sadroddini, M. Razzaghi Kashani and N. Khoramabadi, Antibacterial ethylene propylene rubber impregnated with silver nanopowder: AgNP@EPR, Nano. Chem. Res., Vol.1, No.1, (2016).

[35] Farouk S Nas, Muhammad Ali and Aminu Muhammad A, Application of Nanomaterials as Antimicrobial Agents: A Review, Arch Nano Op Acc J. Vol.1, (2018). 